Reviews in Digital Humanities • Vol. 2, No. 3

\title{
Review: Tribesourcing Southwest Film Project
}

\author{
Carl Teegerstrom 1 \\ ${ }^{1}$ University of Texas at Austin
}

Published on: Mar 08, 2021

DOI: $10.21428 / 3 e 88 f 64 f . f 43418 d d$

License: Creative Commons Attribution 4.0 International License (CC-BY 4.0). 


\section{Project}

Tribesourcing Southwest Film Project

\section{Project Team}

Jennifer L. Jenkins, Project Director, University of Arizona

Melissa Dollman (Yankton Sioux), Digital Project Manager, University of North

Carolina at Chapel Hill

Rhiannon Sorrell (Diné), Project Narrator Coordinator, Diné College

\section{Project URL}

https://tribesourcingfilm.com/

\section{Project Reviewer}

Carl Teegerstrom, University of Texas at Austin

\section{Project Overview}

\section{Jennifer L. Jenkins, Melissa Dollman, and Rhiannon Sorrell}

Our NEH-funded project seeks to "tribesource" mid-century educational films about Native peoples of the Southwestern U.S. from the American Indian Film Gallery_, a legacy digital collection held at the University of Arizona (UA). Products of the golden age of $16 \mathrm{~mm}$ Kodachrome cinematography, these films often present quite remarkable visuals of places, people, and cultural practices across Indian Country. The original narrations, by contrast, represent a dark age of cultural bias and misrepresentation. At this historical distance, many of these films have come to be understood by both cultural insiders and outside scholars as documentation of cultural practices, lifeways, and languages that are receding as practitioners and speakers pass on. We have sought to repurpose and decolonize these films by taking them back into the Native communities where they were made in the 1930s-1950s and inviting community members to record new, culturally-competent narrations in Indigenous and/or European languages as alternate audio tracks to the legacy visuals.

This project combines digital preservation of 20th century $16 \mathrm{~mm}$ educational and sponsored films with 21st century interpretation of the films' content specific to Native cultures of the Southwest. Tribesourcing places historical materials with the peoples they represent to tell untold or suppressed stories. As a methodology, it draws upon history, storytelling, material culture, languages, arts, geography, lifeways-all 
understood from Native perspectives. A small step toward cultural repatriation of content, the project is guided by the Protocols for Native American Archival Materials (2006). ${ }^{1}$ Tribal Coordinators identify and record counter-narrators' English and Native language narrations. All narrators are monetarily compensated for their time and contribution.

We chose the Mukurtu content management system (CMS) because it provides for community implementation of the Protocols both logistically and methodologically. The platform's own "Protocols" function provides for community control over access to cultural materials therein. Additionally, through Mukurtu's integration of Local Contexts' Traditional Knowledge (TK) Labels, members can attribute iconographic labels that denote cultural restrictions under which materials can or cannot be viewed (e.g. gender or seasonal conditions).

Mukurtu incorporates into its user interface Google Maps, third-party HTML5 video and audio players, and linked metadata among films. All files, except for videos, are stored within the CMS. For integrating and streaming large video files, we chose Vimeo. ${ }^{2}$ The UA's servers originally hosted the Tribesourcing site and all of its content. Precipitated by a need for timely control over practical technical aspects such as upgrading the software, we moved the project to Reclaim Hosting's shared-hosting services. ${ }^{3}$ Our team also felt an ethical obligation to forestall the UA's potential proprietary control of information, as all material on university servers is owned by the Board of Regents.

All digital files are backed up in the cloud and on geographically-dispersed hard drives. Quality control checks occur at each stage: recording, file transfer, uploading of new audiovisual files, and file migration to newer preservation and access formats when necessary. Mukurtu is maintained and secured with each new software update.

The audience for this project is quite diverse: tribal members and cultural preservation officers; families; educators across the spectrum; museum professionals; scholars interested in non-theatrical audiovisual media. The essence of this project is engaging new audiences, both Native and non-Native, to actively decolonize and critically reexamine the audiovisual record. We gratefully acknowledge funding from University of Arizona and the National Endowment for the Humanities from the inception of this project-in-progress to date. The project has been used in the Navajo Cultural Arts program at Diné College, at Santa Fe Indian School, and is being replicated at Northern Arizona University. 
1. Protocols for American Indian Archival Materials, Northern Arizona University, http://www2.nau.edu/libnap-p/ (Accessed September 8, 2020).

2. Moving to Reclaim's shared hosting was not a seamless process. Unfortunately, we encountered one insurmountable issue: streaming such large video files directly from the content management system. Mukurtu as a platform can stream video and audio files through its interface, and when the project's newly digitized film files were stored on the university servers, we did just that, despite the fact that the file sizes range anywhere from $750 \mathrm{MB}$ to $3 \mathrm{~GB}$, depending on length. However, files of these sizes continually surpassed the maximum execution time limit for PHP processing allowed by Reclaim for uploading. Grant dollars had paid for higherresolution scans of the films, and we were committed to offering the best quality access copies. Thus, we chose to use stream files from Vimeo at the Mukurtu support team's suggestion. Vimeo has multiple safeguards in place that allow the user to hide videos from searches within their website and from the Internet. The communities still control the protocols and community standards for each video on the Tribesourcing site itself, and we are able to deliver a high-quality viewing copy of the film. While creating this workaround was unexpected, both Mukurtu and Reclaim Hosting's support teams worked diligently to help us utilize the platform as we originally intended.

3. Fortunately Reclaim integrates rather well with Mukurtu, including an option to automatically update the software upon new release.

\section{Project Review}

\section{Carl Teegerstrom}

The Tribesourcing Southwest Film Project (TSFP) sources and hosts updated, culturally-competent narrations of films about Native peoples of the Southwestern U.S. recorded between the 1930s and 1950s. Now held as part of the American Indian Films Gallery housed at the University of Arizona, TSFP seeks to decolonize the "remarkable visuals of places, people, and cultural practices" by separating them from the originally-recorded narrations which "represent a dark age of cultural bias." Partnering with members of the Navajo/Diné, Apache/Inde, and Akimel O'odham/Pima nations as well as with other Southwest communities, films are recorded in both English and the relevant Indigenous languages. All narrators are vetted by the appropriate tribal communities. These newly-revised films then represent a model for repatriating and reappropriating content produced in the process of colonization. 
The technological infrastructure of the project supports its decolonizing goals through its use of the Mukurtu content management system. Built with Indigenous content in mind, Mukurtu allows for Indigenous communities to have greater control over the release of their materials. The inclusion of Indigenous forms of knowledge through traditional knowledge labels allows communities to add information about access, use, and circulation to third parties. Here, we see how autonomy and repatriation can be clearly articulated as part of the technological infrastructure of the project. Users can browse the collections by community name, category/type of film, review status, keywords, and type of media.

Usefully for those unfamiliar with Indigenous communities of the Southwest, TSFP provides a dictionary for the included Indigenous languages. The dictionary can be faceted by language, keywords, parts of speech, and translation. Complementing the dictionary is the "How-To" section of the site, which provides a step-by-step set of instructions for finding the narrated films, viewing the videos, and listening to the audio. Given that the project seeks to reach Indigenous elders who may be less familiar with the Murkutu platform, these directions are quite helpful. In development are three teachers' modules on "Natives \& the Film Age," "The Trading Post \& Pawn Economics," "Tuberculosis among the Navajo." Each are situated well to highlight the content within the newly narrated videos.

Future developments that TSFP might also consider are related to contextual information. TSFP is to be commended for the detailed descriptions of the contents of each film. Additional contextual analysis beyond descriptive metadata might assist users with understanding both the significance of the content of the videos as well as the highly problematic conditions of their production. As TSFP rightly point out on both the project website and in their overview, these films are legacies of misinterpretation and extractive practice. Non-native users are likely to have little understanding of the harm that these films cause and may need to be gently cautioned about potential misuse of the information by non-culturally-competent people. 